BULL. AUSTRAL. MATH. SOC.

I0F 35

VOL. $14(1976), 477-478$.

\title{
On the transcendency of the solutions of a special class of functional equations: Corrigendum
}

\section{Kurt Mahler}

Mr V.E. Hoggatt, $\mathrm{Jr}$, has pointed out an error in the examples of my paper [2]. If $F_{m}$ denotes the $m$ th Fibonacei number, these examples asserted that

$$
\sum_{n=0}^{\infty}\left(F_{2^{n}}\right)^{-1},=s \text { say, }
$$

is transcendental. This is in fact false, for by a theorem of Good [1],

$$
s=(7-\sqrt{5}) / 2 ;
$$

for it happens that

$$
\sum_{n=0}^{\infty} z^{2^{n}}\left(1-z^{2^{n+1}}\right)^{-1}=\frac{z}{1-z}
$$

is a rational and not a transcendental function of $z$, so that Theorem 1 of my paper cannot be applied. The value of 8 follows from (1) on putting $z=\frac{1-\sqrt{5}}{2}$.

Hence the following changes have to be made in [2].

On p. 390, lines 7 and 10, the case $k=1$ must each time be excluded, and in Theorem 2 the two numbers $r$ and $s$ may not be both be 0 .

Received II February 1976. 


\section{References}

[1] 1.J. Good, "A reciprocal series of Fibonacci numbers", Fibonacci Quart. 12 (1974), 346.

[2] Kurt Mahler, "On the transcendency of a special class of functional equations", BulZ. Austral. Math. Soc. 13 (1975), 389-410.

Department of Mathematics,

Institute of Advanced Studies, Australian National University, Canberra, ACT. 